\title{
Inclusive Teaching in Isolating Situations: Impact of COVID-19 on Efforts Toward Increasing Diversity in BME
}

\author{
Memoria E. Matters (iD, ${ }^{1}$ Andrew O. Brightman, ${ }^{2}$ Patrice M. Buzzanell $\mathbb{0}{ }^{3}$ \\ and CARla B. ZOLTOWSKI \\ ${ }^{1}$ School of Engineering Education, Purdue University, West Lafayette, IN 47907, USA; ${ }^{2}$ Weldon School of Biomedical \\ Engineering, Purdue University, West Lafayette, IN 47920, USA ${ }^{3}$ Department of Communication, University of South Florida, \\ Tampa, FL 33620, USA; and ${ }^{4}$ Schools of Electrical and Computer Engineering and (by Courtesy) Engineering Education, \\ Purdue University, West Lafayette, IN 47907, USA
}

(Received 29 June 2020; accepted 24 July 2020; published online 20 August 2020)

As part of National Science Foundation (NSF) sponsored Research in the Formation of Engineers (RFE), we have been focusing on inclusive teaching strategies for engineering professors. Now, in the presence of a pandemic and protests for racial justice in America, underrepresented students are facing unprecedented challenges as they navigate new situations of remote learning. What does inclusive teaching look like in this new context, and what does this mean for teaching in the future?

\section{BACKGROUND}

Our research group was formed to investigate the intersection of three goals in engineering education: professional formation of students, diversity and inclusion, and a sociotechnical perception of engineering. We approached these goals with design thinking in collaboration with faculty, staff, and students in a comparative study of two engineering departments - electrical and computer engineering (ECE) and biomedical engineering (BME) - at a large, research-intensive university. In our recent work, we have highlighted the importance of faculty support for engineering students, especially those in underrepresented groups. Through interviews, we found that BME undergraduate students felt they were "on their own" to navigate the system of getting their degree and finding jobs. ${ }^{1}$ They felt it was up to them to learn effective study habits, find a practical specialization,

Address correspondence to Memoria E. Matters, School of Engineering Education, Purdue University, West Lafayette, IN 47907, USA. Electronic mail: matters@purdue.edu and seek out professional development opportunities. However, all of those skills are heavily influenced by students' previous knowledge and experience, or cultural and social capital, within the world of engineering. If it is left up to students to navigate the complexities of a career in BME, then underrepresented and underprivileged students, who are less likely to have the types of cultural and social capital typically expected for that career, are at a distinct disadvantage for success. Therefore, if professors become more engaged with their students both inside and outside of the classroom, it can help level the playing field among a diverse student body.

A call for stronger relationships between engineering professors and students has a strong precedent in the literature. To aid the persistence of underrepresented STEM students, it is important that professors foster their interest, capacity, and belongingness in their field. ${ }^{2}$ Stronger faculty-student relationships are associated with higher performance and confidence in students, ${ }^{3}$ while student-perceived distance from faculty may actually harm self-efficacy and confidence. ${ }^{4}$ The evidence implies that to teach inclusively means to actively form relationships with students, work to understand them individually as people, and engage in "informal mentoring" in everyday classes and office hours. This means that inclusive teaching takes work. To professors already juggling a multitude of responsibilities, personally investing in students can become an emotional, professional, and even financial burden. ${ }^{5}$ We observed this conflict in our interviews with ECE professors, who perceived a lack of resources and support to take action for diversity and inclusion. ${ }^{6}$ As one resulting intervention, we developed inclusive teaching "tip sheets" targeted at both the ECE and BME departments that lists simple inclusive practices 
intended to take little extra time or resources for professors to implement. Examples include showcasing in class a wide variety of career paths related to the course material, addressing students by name, and deliberately inviting students to office hours. All of these tips, of course, assumed an in-person learning environment which suddenly evaporated when campuses across the country shut down and/or moved to remote learning in the wake of the coronavirus pandemic.

\section{CHALLENGE: DIVERSITY AND ISOLATION}

Campus shutdowns and self-isolation suddenly disrupted every aspect of university operation and the lives of students, faculty, and staff. Professors are scrambling to redesign courses for remote learning amid the wider community's uncertainty about financial stability, social isolation, and the virus itself. In a time of heightened stress and physical separation for both instructors and students, the idea of faculty-student connection has become obscure. If BME students felt they were "on their own" before the coronavirus, now they are more on their own than ever. What does this situation mean for underrepresented and underprivileged students?

Some students in BME have noted recently that their family and living situations make it difficult to complete school assignments on time and communicate with their classmates for team assignments. These are just some ways that the switch to online learning has affected students in unanticipated ways. Without the "equalizing" environment of the classroom and campus, students' differences in economic as well as cultural and social capital are exacerbated. Many students do not have access to a quiet place at home to do their schoolwork, or reliable access to a computer with internet. Many low-income students relied heavily on university resources for food, housing, and healthcare. When those resources were suddenly shut down, some students who were told to leave campus had nowhere else to go. ${ }^{7}$ Underprivileged students have had to navigate online learning while also dealing with unexpected expenses, loss of jobs and housing, and worry about the health and safety of themselves and their families.

To complicate matters, the recent national attention on racism in America and the resurgence of the Black Lives Matter movement after the death of George Floyd have disrupted black students' lives further by bringing their trauma to the surface. Many black students have been forced to become activists for their own survival, while recognizing that the universities they attend are in many ways complicit in institutional racism. ${ }^{8}$ These students are attempting to continue their coursework while the country publicly debates their right to live.

In all the above ways, diversity and inclusion in higher education are more relevant than ever, especially at the critical nexus of professional formation and sociotechnical integration, and yet because of remote learning and other isolating situations appears harder to support.

\section{NOVEL INITIATIVE: INCLUSIVE REMOTE TEACHING}

How can the BME educational community bring much needed support to underrepresented students during isolation? What is inclusive teaching in the context of remote instruction? Although remote learning has changed the mechanics of how instructors are able to interact with students, the spirit of our inclusive teaching tip sheet remains. It is a set of strategies grounded in compassion and support, and made to foster interest, capacity, and belongingness in underrepresented students. In this section, we reimagine each of our tips in the current context of isolating situations. Where possible, we point to examples of some specific virtual tools that instructors can use in their remote learning courses.

\section{Interest}

Students need to feel that course material is important and relevant to the world and their own futures. Amid the current uncertainty, students may be struggling more than usual to stay engaged in course topics and see the true impact of what they are learning. Our tips for fostering interest in remote learning courses are:

- Incorporate active learning to keep students engaged: Although active learning in a remote class may sound daunting, there are many tools available to create engaging activities virtually. If teaching through Zoom or Webex, you can carry out pair-and-share activities and other discussions using breakout rooms. Zoom is also capable of hosting a live collaborative whiteboard where students can share ideas. You can also create live quiz games and other activities with Kahoot!. 
- Connect course material to the real world and people: Just as in in-person courses, continue to spend time in remote lectures explaining the realworld applications and impacts of what you teach. Including discussions of recent biomedical engineering research and responses to COVID-19, both from your own campus as well as globally, is a prime example.

- Showcase career paths which use your course material: Invite guest speakers working in the area of your course to your remote lectures to talk about their work and take questions. Also, provide students with links to videos about the wide variety of careers in BME (the NSF and the American Institute for Medical and Biomedical Engineering (AIMBE) websites are just two sources) and follow-up with online discussions related to student submitted questions.

- Embed research experiences into courses: Integrating research into courses is vital to fostering interest, but it is made difficult by the lack of access to laboratories during social distancing. To continue emphasizing the connection between course material and research, you can create class activities or assignments where students design an experiment and get feedback. You can also have students find examples of BME research online to post in discussion boards.

\section{Capacity}

Students' capacity in engineering includes both their ability and perceived ability, or self-efficacy. In other words, students need to feel capable of succeeding in the field. The extra challenges of remote learning, in which students have less access to academic support from instructors, staff, and peers, can be damaging to students' confidence. Fostering students' capacity involves using a growth mindset, or the belief that ability is not fixed but can change, in order to encourage students to keep trying. Our tips for fostering capacity through remote learning are:

- Understand and accommodate differences in resources: As discussed above, not all students have access to ideal remote learning conditions. Be aware of assumptions you could be making about students' resources (technology, time, living conditions, etc.) and have a plan to accommodate students' unique situations when necessary.
- Provide consistent feedback so students can recognize their progress: Just as in in-person courses, return graded exams and assignments as soon as possible so students can correct course early. The remote learning context also provides opportunities to leverage auto-grading capabilities of Learning Management Systems and other digital technologies (e.g. Gradescope, Crowdmark, etc.).

- Provide opportunities for students to build confidence: When creating assignments, break up longer problems and projects into distinct steps so they are less overwhelming. Also, an important way that students can build confidence is through group work (as long as their contributions are valued); however, group assignments can be tricky to implement remotely. To help alleviate communication issues between group members, you can create defined roles for group members and help groups establish a communication plan before starting the project.

- Destigmatize students needing help: Some students may be nervous about attending office hours, and the unfamiliar format of virtual office hours may make them even less likely to attend. Hold virtual office hours and make it clear to students that they are welcome and that you want to help them. Additionally, provide an asynchronous way for students to ask questions - even anonymously - through a discussion board like Piazza.

- Embrace questions in class: Praise students asking questions during remote lectures by saying "Thanks for asking," or "Good question," to encourage more questions. You can also use the Zoom or Webex chat feature or Hotseat to make it easier for students to ask questions.

\section{Belongingness}

Students need to feel that people like them belong in the field. Since belongingness is influenced by visible role models and strong relationships at school, this is one of the most difficult factors to work toward in a remote setting. However, given the particular struggles of underrepresented students during this time, it is also one of the most important. Our tips for belongingness adapted to remote learning are:

- Model authenticity and vulnerability: Acknowledging your own challenges and life situation in the pandemic as well as your struggles with online technology and virtual teaching can provide a 
connection point for students. Asking for student suggestions on how to make the virtual classroom feel more connected can also encourage a sense of belonging in the class, even if means potential for introducing some changes to the routine.

- Include diverse students in class participation: When taking questions during remote lectures, ask to hear from students who haven't spoken yet so that a diverse set of voices is heard. Providing short interactive activities for peers to get to know each other in virtual breakout rooms can also enhance belonging in the virtual classroom.

- Use diverse engineers as examples: Just as in inperson courses, showcase the accomplishments of diverse engineers when discussing real-world examples and represent diversity in any imaginary characters you create for practice problems. The virtual classroom allows opportunities for guest appearances from diverse academic and industry colleagues who might otherwise not be able to attend in-person due to distance and time commitments.

- Show interest in individual students: During remote learning, students may feel especially disconnected from instructors. To let students know you care, you can learn students' names and address them by name, even in remote lectures. At the beginning of the term, create an introduction activity (during lecture or via student-made videos) to get to know your students. If possible, schedule one-on-one meetings with students to check how they are doing in the course and in life. These extra interactions can make a big difference to students' sense of belonging.

- Promote diversity in student leadership roles: Recognizing that student activities and employment have been limited by restrictions of the coronavirus, it is still important to consider representing diversity when you do have opportunities to offer students (such as undergraduate research positions or assistantships).

These are just a few examples among many and varied options of inclusive teaching practices that can be adapted for remote learning. We encourage instructors to consider how other inclusive strategies from their own experiences and from colleagues can be incorporated into remote instruction. The work for increasing diversity and inclusion in BME is inherently difficult - it requires introspection and a willingness to make mistakes ${ }^{9}$ - and the current circumstances might make it seem even more daunting. However, those circumstances' effects on underrepresented students is precisely why this work is so important now. Therefore, despite the general uncer- tainty and chaos during this time, it is especially vital that instructors remember to consider inclusion in their course designs.

\section{REFLECTION: WHAT'S NEXT?}

In our current study, we are conducting interviews with faculty members of the ECE and BME departments to determine the effects of the inclusive teaching tip sheets and their own experiences on their intention to use inclusive teaching strategies in their classrooms. Thus, this exploratory study is focused on the extent of usage of inclusive strategies by engineering faculty. With this data, we will be able to identify school policies and intervention strategies that encourage inclusive teaching among engineering professors. In the wake of current events, the interviews also investigate how remote teaching has affected the participants' ideas of inclusivity in teaching. As diversity and inclusion have recently been brought to the forefront of world dialogues, perhaps these experiences can help refocus the BME community on inclusion beyond the current crises.

The coronavirus pandemic combined with the current political crisis in America will certainly have lasting effects on many aspects of life, including higher education. As members of academia during this time, we are helping to decide what those effects will be. We are at a critical moment where we are all reminded of our humanity: our differences, our emotions, and our mortality. What if we use this experience to regroup around compassion? What if we let the current crises lead us to more human-centered teaching in the future?

\section{AUTHOR CONTRIBUTIONS}

The first draft of the manuscript was written by MEM and all authors commented on previous versions of the manuscript. All authors read and approved the final manuscript.

\section{FUNDING}

This work was made possible by a grant from the National Science Foundation (EEC-1636446). Any opinions, findings, and conclusions or recommendations expressed in this material are those of the authors and do not necessarily reflect the views of the National Science Foundation.

\section{CONFLICT OF INTEREST}

The authors report grants from the National Science Foundation during the conduct of the study. 


\section{CONSENT TO PARTICIPATE}

For the interviews used to inform these teaching tips, informed consent was obtained from all individual participants.

\section{ETHICAL APPROVAL}

Approval for the engineering education research was obtained from the Institutional Review Board of Purdue University. The procedures used in this study adhere to the tenets of the Declaration of Helsinki.

\section{REFERENCES}

${ }^{1}$ Corple D, Zoltowski CB, Eddington S, Brightman AO, Buzzanell PM. What you need to succeed: examining culture and capital in biomedical engineering undergraduate education. Presented at ASEE, Tampa, FL, 2019. https://peer.a see.org/33556.

${ }^{2}$ Packard BWL. Successful stem mentoring initiatives for underrepresented students: a research-based guide for faculty and administrators. Sterling: Stylus; 2016.

${ }^{3}$ Micari M, Pazos P. Connecting to the professor: impact of the student-faculty relationship in a highly challenging course. Coll Teach. 2012;60(2):41-7. https://doi.org/10.108 $0 / 87567555.2011 .627576$.

${ }^{4}$ Vogt CM. Faculty as a critical juncture in student retention and performance in engineering programs. J Eng Educ. 2008;97(1):27-36. https://doi.org/10.1002/j.2168-9830.2008. tb00951.x.

${ }^{5}$ Schwartz J. Faculty as undergraduate research mentors for students of color: taking into account the costs. Sci Educ. 2012;96(3):527-42. https://doi.org/10.1002/sce.21004.

${ }^{6}$ Matters ME, Zoltowski CB, Brightman AO, Buzzanell PM. An engineering faculty and an intention to make change in diversity and inclusion: creating sustainable change efforts. Presented at CoNECD, Crystal City, VA, 2021. Forthcoming.

${ }^{7}$ Weissman S. The underrepresented, underprivileged hit hard by coronavirus-related campus closures. Diverse Issues in Higher Education. 2020. https://diverseeducation.com/a rticle/173382/.

${ }^{8}$ Chiles M. STUDENT VOICE: 'College students like me were stopped in their car by police and subsequently tased and beaten for trying to get home.' The Hechinger Report. 2020. https://hechingerreport.org/student-voice-the-currentgenerations-civil-rights-movemement/.

${ }^{9}$ Chesler NC. A how-to guide for promoting diversity and inclusion in biomedical engineering. Ann Biomed Eng. 2019;47(5):1167-70. https://doi.org/10.1007/s10439-019-022 $23-2$.

Publisher's Note Springer Nature remains neutral with regard to jurisdictional claims in published maps and institutional affiliations. 